\title{
Infection and Colonization of Several Bermudagrasses by Ophiosphaerella korrae
}

\author{
F. J. Flores, S. M. Marek, J. A. Anderson, T. K. Mitchell, and N. R. Walker
}

First, second, and fifth authors: Department of Entomology and Plant Pathology, Oklahoma State University, Stillwater 74078; third author: Department of Horticulture, Oklahoma State University, Stillwater 74078; and fourth author: Department of Plant Pathology, The Ohio State University, Columbus 43210.

Accepted for publication 8 December 2014.

\begin{abstract}
Flores, F. J., Marek, S. M., Anderson, J. A., Mitchell, T. K., and Walker, N. R. 2015. Infection and colonization of several bermudagrasses by Ophiosphaerella korrae. Phytopathology 105:656-661.

Bermudagrass (Cynodon spp.) is the most commonly used turfgrass in the southern United States where it is severely affected by spring dead spot (SDS) caused by Ophiosphaerella herpotricha, $O$. korrae, and $O$. narmari. In this study, infection of bermudagrass roots and stolons by $O$. korrae was characterized using a transformant that expressed the red fluorescent protein tdTomato. Roots of interspecific hybrid cultivars Midlawn and Tifway 419, C. transvaalensis accessions Uganda and 3200 , and C. dactylon cultivar U3 were inoculated and observed from 2 to 14 days postinoculation (DPI) while stolons were observed from 2 to 22 DPI. For all five cultivars tested, a similar

level of root colonization was observed; however, differences were observed in the rate of necrosis development. Necrosis of Tifway 419 and Midlawn tissues was evident at 2 DPI, in Uganda and 3200 at 8 DPI, and in U3 necrosis was often absent as late as 14 DPI. The fungus rapidly penetrated the root epidermis and colonized the cortex of all cultivars by 4 DPI. Colonization of stele tissues by $O$. korrae was rare in hybrid cultivars but common in C. transvaalensis and C. dactylon accessions. On intact stolons, the fungus did not penetrate the epidermis 22 DPI though epidermal necrosis was evident on the surface of only the hybrid bermudagrasses. Wounded stolons became necrotic in all cultivars. Infection and colonization of various bermudagrasses by $O$. korrae was found to be similar to that by $O$. herpotricha, suggesting that host genetic resistance may be used for effective management of SDS caused by both species.
\end{abstract}

Bermudagrass (Cynodon dactylon (L.) Pers.) and its hybrids (C. dactylon $\times$ C. transvaalensis Burtt-Davy) are the most commonly used turfgrasses in the southern United States where cool-season grasses are difficult to maintain. The two greatest limitations for extending the range of improved varieties further north are susceptibility to cold temperature injury and a disease known as spring dead spot (SDS) (7). SDS is considered the most destructive disease of bermudagrass where low temperatures induce grass dormancy (15). It is often associated with highly maintained bermudagrasses and is caused by one of three fungi in the genus Ophiosphaerella, namely O. herpotricha (Fr.) Walker, O. korrae (J. Walker and A. M. Smith) R. A. Shoemaker and C. E. Babcock, or O. narmari (J. Walker and A. M. Smith) Wetzel, Hubert and Tisserat $(5,8,19,20,22,25-27)$. In the United States, $O$. herpotricha is more common in the Midwest and $O$. korrae more common in the Southeast (27). The presence of the latter two species, and occasionally all three species, at a single location can occur and is likely due to the movement of infested plant material (27). Since effective management of SDS can be costly and difficult, knowledge about the etiology of the pathosystem is critical for developing effective control methods.

The fungi that cause SDS are described as ectotrophic, rootinfecting fungi that colonize the surface of below-ground organs, such as roots and rhizomes, prior to infection. After colonization, hyphae will directly penetrate the epidermis or enter through wounds that can be common on rhizomes and stolons of turfgrasses that are subjected to wear, herbivore damage, dethatching, or aerification

Corresponding author: N. R. Walker; E-mail address: nathan.walker@okstate.edu

*The $\boldsymbol{e}$-Xtra logo stands for "electronic extra" and indicates that three supplementary figures are published online.

http://dx.doi.org/10.1094/PHYTO-07-14-0205-R

(C) 2015 The American Phytopathological Society
$(3,20)$. When colonizing a host, $O$. korrae produces brown, septate hyphae ( 2.5 to $5 \mu \mathrm{m}$ wide) and dark brown strands of runner hyphae, which accumulate into infection mats on the root surface $(4,26)$. All Ophiosphaerella species that cause SDS can colonize roots, stolons, or rhizomes, and localized necrosis can be observed within days after inoculation (24). When bermudagrass growth slows due to low temperatures, the fungus can rapidly colonize below-ground host tissues, resulting in localized symptom development on these tissues (4). In the autumn, the healthy appearing bermudagrass enters cold temperature-induced dormancy. Additional tissue necrosis occurs during the winter leading to infected plant death and the appearance of dead patches of grass once temperatures warm and noninfected grass resumes growth in the spring.

Host-pathogen interactions at the cellular level have been previously described for the $O$. herpotricha pathosystem on bermudagrasses (3). Roots and stolons of $C$. dactylon $\times C$. transvaalensis (hybrid bermudagrass) and $C$. transvaalensis were infected with an isolate of $O$. herpotricha that expressed green fluorescent protein (GFP) and red fluorescent protein (tdTom). Roots of two hybrid bermudagrass varieties, Midlawn, which is moderately susceptible to SDS, and Tifway 419 , which is very susceptible, both developed large necrotic lesions when colonized by $O$. herpotricha in vitro. In an accession of $C$. transvaalensis, a more tolerant endophytic-like association occurred with $O$. herpotricha, in which the fungus colonized the stele and limited necrosis was observed (3). Stolons of both hybrids and $C$. transvaalensis were colonized; however, C. transvaalensis exhibited little to no necrosis, suggesting an inherent tolerance to $O$. herpotricha (3). Host response to infection and colonization was a suggested contributor to plant death caused by SDS during dormancy (3).

SDS can occur on other warm-season grasses including zoysiagrass (Zoysia spp.) and buffalograss (Buchlö̈ dactyloides) $(10,21,23)$. Ophiosphaerella. korrae is also the causal agent of necrotic ring spot on Kentucky bluegrass (Poa pratensis), a cool- 
season turfgrass species $(6,18)$. Knowledge about the processes of infection, colonization, and pathogenicity of $O$. korrae for bermudagrass is limited $(4,8)$. It is also not known how the fungus interacts with the plant at a cellular level when colonizing susceptible and resistant bermudagrass varieties. Historical differences in virulence, host range, geographic distribution, and taxonomic placement between $O$. korrae and $O$. herpotricha suggest that the interaction of these two fungi with hosts may differ. The objective of this study was to characterize the infection and colonization of $O$. korrae in several bermudagrass cultivars having different levels of resistance. By utilizing an isolate that expresses fluorescent proteins, the goal is to evaluate host responses and to compare pathogenesis events to those previously described for $O$. herpotricha (3).

\section{MATERIALS AND METHODS}

Fungal transformation. Agrobacterium-mediated transformation (AMT) was performed on 23 isolates of $O$. korrae to express either tdTom or GFP, following the protocol described by Caasi et al. (3). Ophiosphaerella herpotricha KS188, an isolate previously transformed, was used as a positive control for the transformation procedure. To determine the rate of transformation, the approximate number of hyphal fragments was obtained by counting the fungal colonies that formed after serial dilutions of the hyphal fragment suspensions were plated on potato dextrose agar (PDA). Pathogenicity and growth rate of the transformed $O$. korrae isolates were compared with those of the wild type. Presence and stability of transgenes were confirmed by antibiotic selection and polymerase chain reaction, and fluorescence microscopy was conducted as described previously (3).

Bermudagrass culture and root inoculation. Aerial stolons from hybrid bermudagrass cultivars Tifway 419 and Midlawn, C. transvaalensis accessions 3200 and Uganda, and C. dactylon cultivar U3 were collected from plants grown at $28^{\circ} \mathrm{C}$ with a $12 \mathrm{~h}$ photoperiod. Stolons were surface-sterilized with a $1.2 \%$ sodium hypochlorite, $38 \%$ ethanol solution for 2 to $4 \mathrm{~min}$, rinsed with sterile, reverse osmosis (RO) water, and cut into 2 to $4 \mathrm{~cm}$ segments, each containing at least one node. Surface-sterilized stolon segments were placed on PDA and incubated in a vertical position for up to 7 days in the dark at $25^{\circ} \mathrm{C}$ to facilitate root growth. Stolons with roots lacking fungal contamination were transferred individually to sterile Petri plates $(100 \times 15 \mathrm{~mm})$ lined with sterile paper towel and placed on a microscope slide $(75 \times 25 \times 1 \mathrm{~mm})$. Aluminum foil on top of a layer of paper towel was used to cover the roots to exclude light. Stolons were left uncovered and exposed to light. Three milliliters of sterile RO water was added to saturate the paper towel. A single root from each stolon was inoculated with an agar plug (approximately $0.25 \mathrm{~mm}$ in diameter) containing mycelium from the edge of a 10- to 14-day-old culture of wild type or transformed $O$. korrae. One noninoculated plant for every four inoculated replicates was used as a control. A minimum of 12 roots of each cultivar were inoculated. Plates were sealed with parafilm and incubated upright in a growth chamber at $17^{\circ} \mathrm{C}$ with a $12 \mathrm{~h}$ photoperiod.

Stolon inoculation. Surface-sterilized stolons having at least one node were either wounded at the internode ( 0.1 to $0.3 \mathrm{~mm}$ deep wounds made with a razor blade) or left intact and inoculated in a similar manner as the roots.

Microscopy. Roots were observed using epifluorescence and light microscopy at 2, 4, 8, and 14 days postinoculation (DPI), and stolons at 3,14, and 28 DPI. Surface colonization by the fungus was observed directly and internal colonization was observed in transverse sections made by hand-sectioning the plant organs, at an approximate width of $50 \mu \mathrm{m}$, with a razor blade. Three different roots or stolons were examined for each DPI stated previously. Whole and sectioned roots or stolons were mounted in water and observed with a Nikon Eclipse E800 microscope (Nikon Inc., Tokyo, Japan) equipped with a mercury-arc lamp, using the UV-2E/C DAPI and G-2E/C TRITC epifluorescence filter sets. Digital images were captured using a monochrome QImaging Retiga 2000R charge-coupled device (CCD) camera (Quantitative Imaging Corp., Surrey, BC, Canada). For each microscopic field, monochrome grayscale images were captured with each epifluorescence filter set and bright field. Each
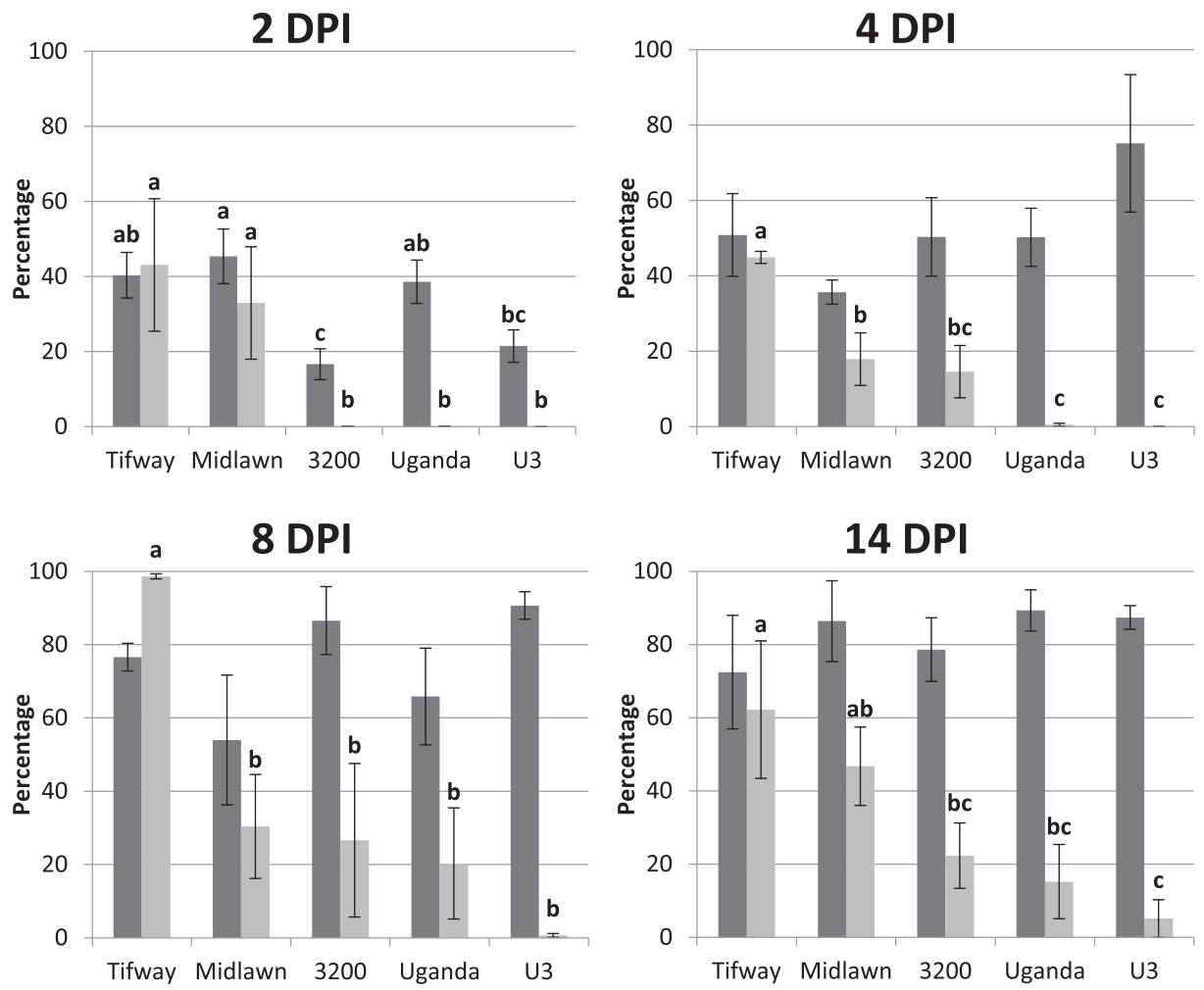

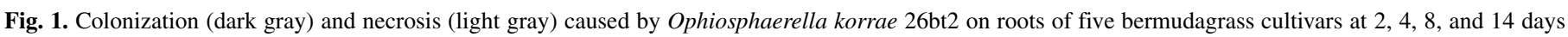

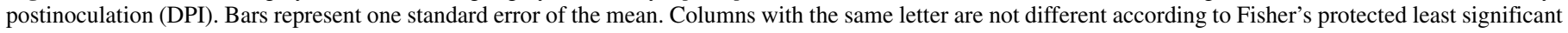
difference test $(P \leq 0.05)$. 
fluorescent image was pseudocolored accordingly and all images were combined as layers over a grayscale bright field image using QCapture Pro version 5.1.1.14 (Quantitative Imaging Corp., Surrey, BC, Canada). Composite images taken at different depths were Z-stacked using AllFocus V1.06 (Saphicon LLC). Color images corresponding to the composites were captured using a Nikon SMZ2T stereomicroscope (Nikon Inc., Tokyo, Japan) equipped with an Olympus DP71 digital camera (Olympus Imaging America Inc., Center Valley, PA). All images used for disease severity ratings were taken at the point of inoculation at $100 \times$ magnification.
Disease severity ratings. Root colonization (red fluorescent from hyphae) and necrosis were assessed for each root. Stereomicroscopic and microscopic pictures were transformed to 3-bit (eight possible colors) images and the number of pixels corresponding to each color was determined using ImageMagick 6.8.5 (ImageMagick Studio, LLC) (Supplementary Fig. 1). Root necrosis was assessed using digital stereomicroscopic images captured over a green background created by placing a clear polystyrene Petri plate tinted green with a permanent marker. The green background of the original picture corresponded to lime and cyan pixels in its 3-bit image

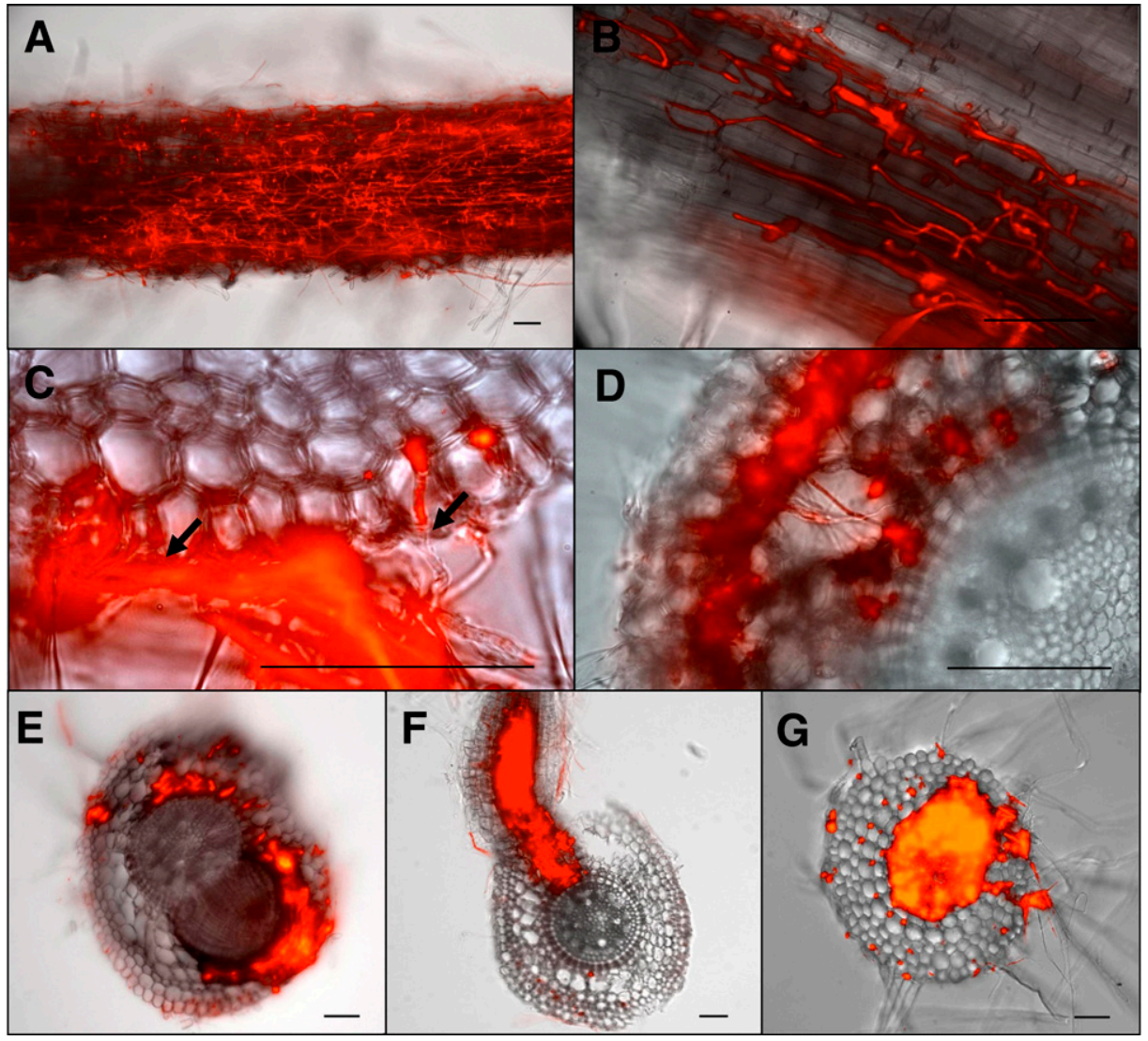

Fig. 2. Epifluorescence images of Ophiosphaerella korrae $26 \mathrm{bt} 2$ colonizing roots of bermudagrass cultivars A, 3200 at 4 days postinoculation (DPI) showing widespread colonization of the root surface, B, Tifway 419 at 8 DPI showing hyphal growth in between epidermal cells, C, Uganda at 2 DPI, with arrows indicating points where hyphae penetrate through and between cells, D, 3200 at 4 DPI showing hyphae growing inter- and intracellularly, E, Tifway 419 at 8 DPI where hyphae did not penetrate into the stele or the emerging lateral root, F, Midlawn at 14 DPI with a lateral root colonized by the fungus after emerging through the epidermis of the main root, and G, U3 at 22 DPI showing colonization of the stele and of an emerging lateral root. Bars represent $50 \mu \mathrm{m}$.

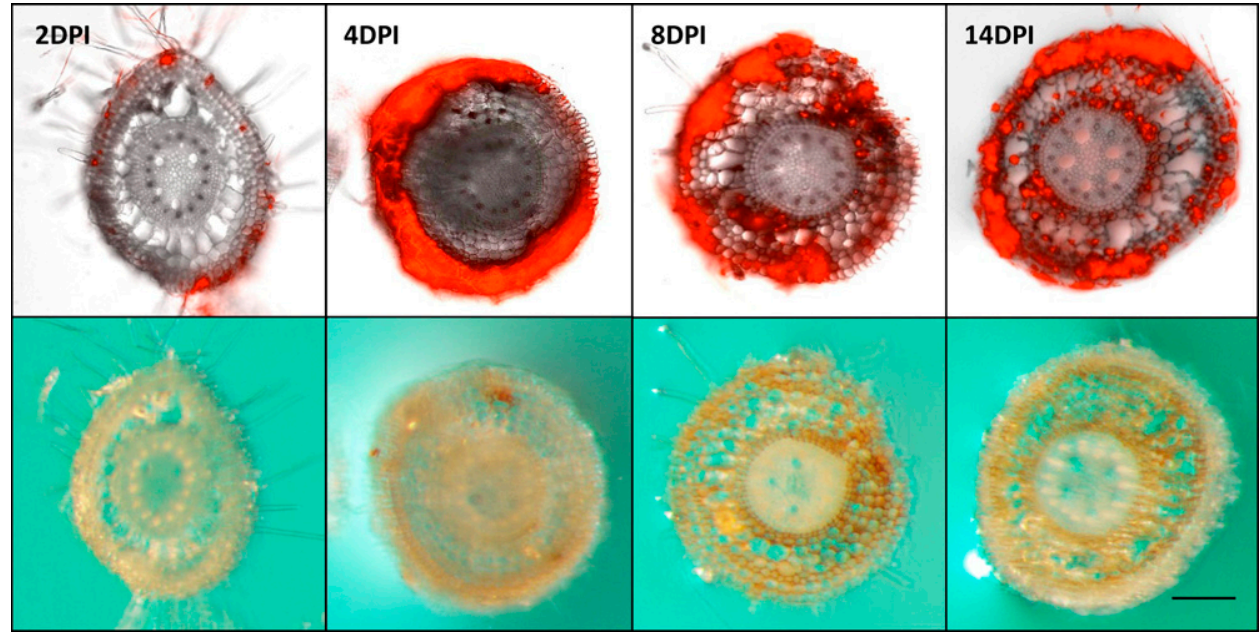

Fig. 3. Transverse sections of Tifway 419 roots exhibiting colonization by Ophiosphaerella korrae 26bt2 at 2, 4, 8, and 14 days postinoculation (DPI). Top row epifluorescence images bottom row bright field. Necrosis of the cortex can be observed starting at 4 DPI. Bar represents $100 \mu \mathrm{m}$. 
counterpart. Total root surface area was obtained by subtracting lime and cyan pixels from the total number of pixels of the 3-bit image. The red and black pixels on the root surface were considered necrotic. Root colonization was assessed in composite pictures using a white background. Relative root surface area was obtained by subtracting the white background from the total number of pixels of the image. The ratio of red pixels (hyphae) to the total pixels within the border of the root surface represented the percentage of root colonized by $O$. korrae. To determine significant differences $(P \leq 0.05)$ in colonization and necrosis between cultivars at each DPI, analyses of variance were performed using the GLM procedure in SAS (version 9.3, SAS Institute, Cary, NC). Where significant, mean separation was conducted using

TABLE 1. Spearman's correlation coefficients $(\rho)$ and probability $(P)$ values for the relationship between Ophiosphaerella korrae colonization and necrosis of roots of different bermudagrass cultivars

\begin{tabular}{lcc}
\hline Cultivar & $\rho^{\mathrm{a}}$ & $P^{\mathrm{a}}$ \\
\hline Cynodon dactylon $\times$ C. transvaalensis 'Midlawn' & 0.75 & 0.005 \\
C. dactylon $\times$ C. transvaalensis 'Tifway 419' & 0.75 & 0.005 \\
C. transvaalensis Uganda & 0.76 & 0.004 \\
C. transvaalensis 3200 & 0.60 & 0.039 \\
C. dactylon 'U3' & 0.52 & 0.086 \\
\hline
\end{tabular}

a Calculated using the CORR procedure in SAS using quantitative data.
Fisher's protected least significant difference test. Spearman's rank correlation coefficient between root colonization by $O$. korrae and necrosis was calculated for each cultivar using the CORR procedure in SAS.

\section{RESULTS}

Fungal transformation. One isolate of $O$. korrae (OW6), was transformed at an approximate rate of 1 transformant per 1,800 hyphal fragments using AMT. Transformants that expressed hygromycin resistance and either GFP or tdTom (two of each) were obtained, with fluorescence of tdTom being brighter than that of GFP. tdTom expressing transformant $26 \mathrm{bt} 2$ appeared culturally similar to nontransformed isolate OW6. Roots of bermudagrass cultivar Midlawn developed necrosis at a similar rate when inoculated with $26 \mathrm{bt} 2$ compared with OW6. Therefore $26 \mathrm{bt} 2$ was chosen for subsequent experiments.

Root colonization. The rate of colonization by $O$. korrae varied among cultivars from 2 to 14 DPI but no significant differences in colonization were observed on most DPI (Fig. 1). One minor difference was observed for bermudagrass accession 3200 roots in which initial colonization was slightly slower than in the other cultivars. For all cultivars, most of the root surface area adjacent to the inoculum was colonized by the fungus by 4 DPI (Fig. 2A), with hyphae growing longitudinally along the root, mainly between the

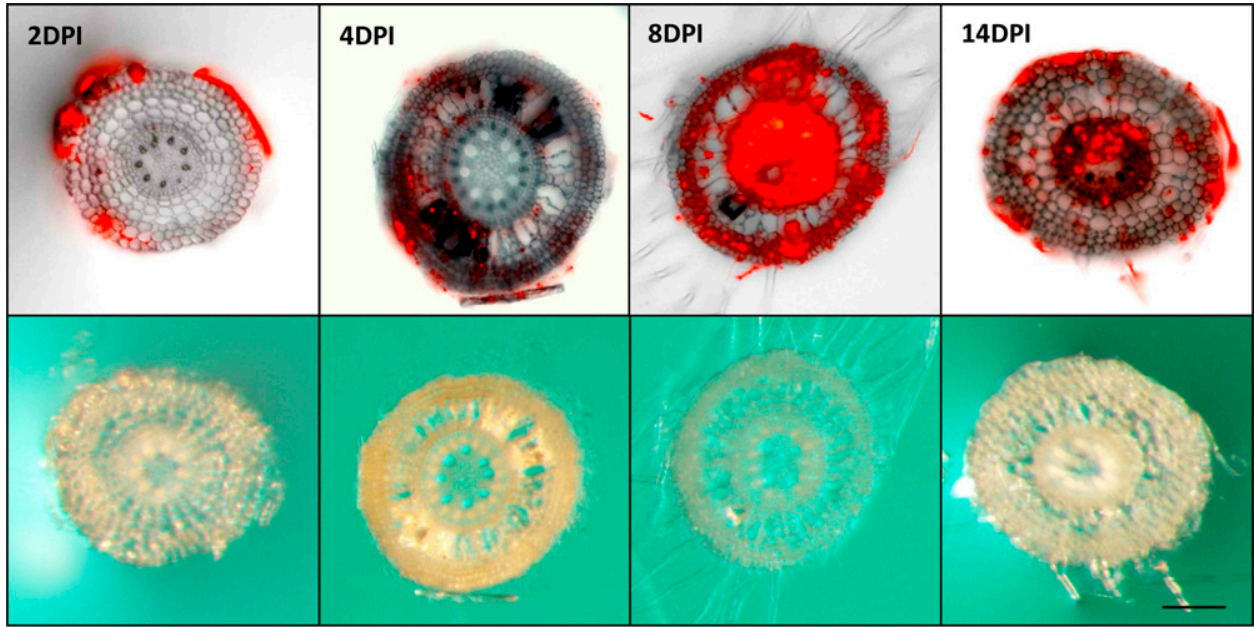

Fig. 4. Transverse sections of U3 roots exhibiting colonization by Ophiosphaerella korrae 26bt2 at 2, 4, 8, and 14 days postinoculation (DPI). Top row shows epifluorescence images, bottom row shows bright field. No necrosis can be observed up to 14 DPI. Bar represents $100 \mu \mathrm{m}$.

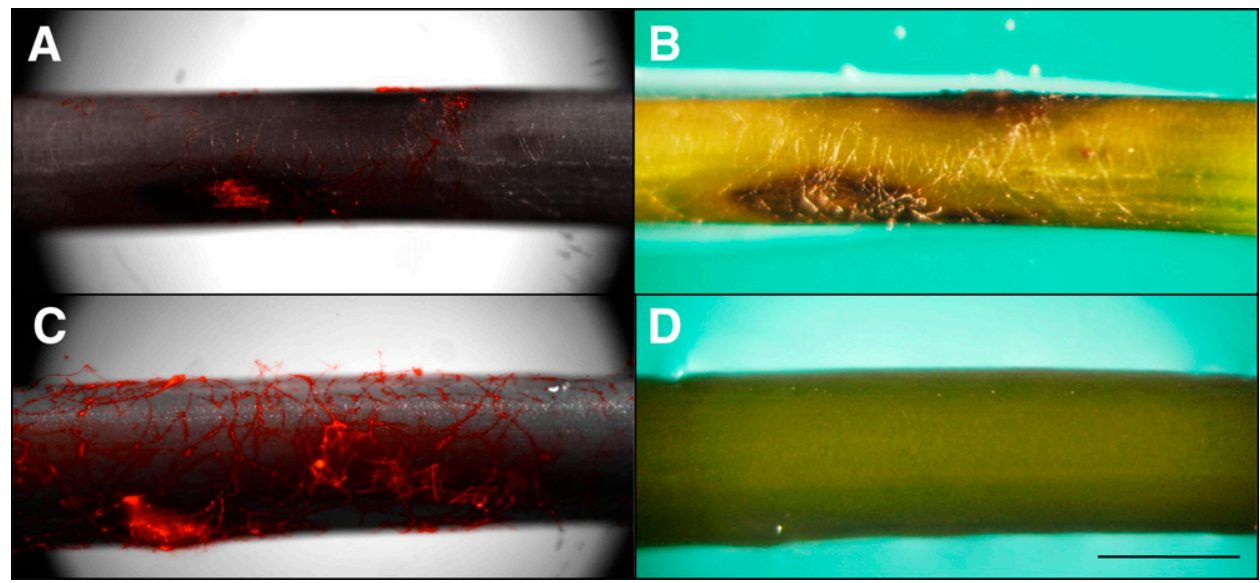

Fig. 5. Stolons of bermudagrass cultivars 18 days postinoculation with Ophiosphaerella korrae 26bt2. Midlawn A, epifluorescence image showing surface colonization and $\mathbf{B}$, bright field image showing symptoms of necrosis. Uganda $\mathbf{C}$, epifluorescence image showing surface colonization and $\mathbf{D}$, bright field image showing no symptoms of necrosis. Bar represents $1 \mathrm{~mm}$. 
root epidermal cells (Fig. 2B). Fungal penetration was similar in all cultivars. The fungus colonized the root surface followed by direct penetration, without specialized structures. By 2 DPI hyphae were observed within and between epidermal cells (Fig. 2C) and once inside the hyphae grew inter- and intracellularly (Fig. 2D). For cultivars Midlawn and Tifway 419, lateral roots were not colonized before rupturing the epidermis of the primary root (Fig. 2E), but roots that had already emerged from the primary root were readily colonized (Fig. 2F). In contrast, for the cultivar U3, in which the fungus had already colonized the stele, lateral roots were colonized before emergence (Fig. 2G). Colonization of root tissues stopped at the endodermis for cultivars Midlawn and Tifway 419 (Fig. 3), with vascular colonization occurring only in a few, short $(<1 \mathrm{~cm})$ roots in which it appeared the fungus colonized this region through the root tip. For cultivars Uganda, 3200, and U3, vascular colonization was more common than for hybrid cultivars (Supplementary Fig. 2), especially in U3 (Fig. 4).

At every DPI observed, cultivar Tifway 419 exhibited the greatest root surface necrosis, followed by Midlawn, 3200, Uganda, and U3, though not all differences were significant (Fig. 1). For Tifway 419 and Midlawn, cortical cell necrosis was apparent as the fungus colonized the tissue (Fig. 3). However, for 3200 and Uganda, the cortex was extensively colonized before necrosis appeared. In U3, necrosis was rarely observed even up to 14 DPI (Fig. 4). The first appearance of necrosis was observed in roots of Tifway 419 and Midlawn by 2 DPI, 4 DPI for 3200, 8 DPI for Uganda, and for U3 by 14 DPI (Fig. 1). Roots in which the vascular tissues were colonized generally did not exhibit symptoms of necrosis (Fig. 4). When $O$. korrae colonized the vasculature in $\mathrm{U} 3$ roots, cortical colonization appeared to decline but the fungus continued to colonize the stele (Fig. 4). In contrast, for Uganda and 3200 the fungus continued to colonize the cortex and vascular tissues. The correlation between root necrosis and colonization was significant $(P<0.05)$ for Tifway 419 , Midlawn, Uganda, and 3200 (Table 1).

Stolon colonization. For all cultivars, the fungus extensively colonized the surface of stolons often forming mycelial aggregations or mats (Fig. 5A and C). Stolons of cultivars Midlawn (Fig. 5B) and Tifway 419 exhibited localized necrotic spots where dense colonization was present, while 3200, Uganda (Fig. 5D), and U3 stolons had only slight discoloration or exhibited no necrosis. For all cultivars observed, the fungus did not penetrate beyond the intact epidermis of stolons when observed at 22 DPI. In contrast, stolon vascular tissues were colonized only when the epidermis and cortex were wounded with localized necrosis being evident by 15 DPI for all cultivars (Supplementary Fig. 3).

\section{DISCUSSION}

Most $O$. korrae isolates tested in this study were not readily transformed using AMT. In general the mycelium of $O$. korrae is more melanized than that of $O$. herpotrich $a$ which likely limited the number of isolates suitable for transformation. The isolate successfully transformed, OW6, exhibited lower melanin content, greater sensitivity to hygromycin, and slower growth than other $O$. korrae isolates. This isolate was transformed at a rate similar to that seen with $O$. herpotricha KS188, which was transformed previously by Caasi et al. (3) and was used as the positive control for the transformation experiments in this study. As previously reported (3) for O. herpotricha, $O$. korrae transformants are indistinguishable from the wild type in disease progression but may grow slower on PDA.

As described previously by Endo et al. (8), O. korrae hyphae colonized cortical cells but runner hyphae were not observed by 14 DPI. The formation of sclerotia was not observed on living plants or in dead and decayed tissues, even after prolonged colonization. The absence of sclerotia is consistent with the findings of Crahay (4), in which resting structures were not observed even 3 months after inoculation. In this study, secondary lateral roots of some cultivars were infected and became necrotic as they emerged and these may have been mistaken to be cortical sclerotia by Endo et al. (8). The formation of cushion-like hyphal aggregates by $O$. herpotricha and $O$. korrae was previously reported at later stages of infection $(3,4)$. In this study, such aggregates were not evident on the roots using bright field microscopy; however, a few, small mycelia mats were observed using fluorescence microscopy. On the surface of inoculated stolons, mycelial mats were formed frequently but did not appear to be associated with penetration of the hyphae into the cortex of the stolon.

Caasi et al. (3) demonstrated that $O$. herpotricha directly penetrated into the cortex of bermudagrass roots, with intracellular hyphae growing longitudinally along the root axis. Ophiosphaerella. korrae also penetrated the root directly and moved along the root axis. A similar infection process has been described for Fusarium oxysporum on tomato, in which the fungus preferentially colonizes the grooves between epidermal cells, has no specific infection sites, and lacks infection structures (13). The surface of tomato roots was colonized and started showing spots of brown discoloration by 4 DPI and hyphal growth in the stele was observed by 6 DPI (13). In contrast with the present study, however, $F$. oxysporum pathogenicity was associated with colonization of the stele on tomato roots that led to the wilting of the plants $(13,17)$. Colonization of the vascular tissues was common with $\mathrm{U} 3$ and seen often in $C$. transvaalensis cultivars, while it was generally not present on hybrid cultivars where it only occurred occasionally after root surface and cortical tissues were completely colonized. Endo et al. (8) observed vascular colonization only in advanced stages of disease development, which suggests that the fungus may penetrate the root tip into the vasculature.

The most severe necrotic response in roots was observed in Tifway 419, a cultivar that is very susceptible to SDS in field studies. In hybrid cultivars Midlawn and Tifway 419, hyphae completely colonized the cortex of the roots growing inter- and intracellularly; however, the vasculature was seldom colonized, as growth stopped at the endodermis. These findings are similar to those of Caasi et al. (3) for these two cultivars. While colonization and necrosis were similar in these two cultivars, SDS severity on Midlawn is significantly less than that in Tifway 419 growing under field conditions (16). Even though greenhouse experiments have failed to relate winter hardiness to SDS resistance for bermudagrass (11), field studies suggest that the greater tolerance to SDS by Midlawn is linked to this cultivar's greater cold tolerance $(1,2,16)$. The $C$. dactylon cultivar designated U3 in this study is not true to type as the original cultivar receiving this designation. The U3 cultivar used in this study was inoculated with SDS in the field and generally did not develop SDS symptoms or if necrotic patches appeared they were very few and small in size while a Tifway 419 stand inoculated at the same time has consistently exhibited severe SDS symptoms for several years (data not shown).

Caasi et al. (3) described less necrosis in C. transvaalensis than hybrid cultivars and sustaining vasculature colonization. In this study, two varieties of $C$. transvaalensis were colonized similarly to the two hybrid cultivars, but had significantly less necrosis compared with Tifway 419. No necrosis was observed on C. transvaalensis when $O$. korrae colonized the vasculature, consistent with what was observed with $O$. herpotricha (3). A striking difference in response to $O$. korrae infection was observed in Tifway 419 and U3; while O. korrae colonized mostly the cortex of Tifway 419 roots and rendered infected cells necrotic as early as 2 DPI, the fungus preferentially colonized the vasculature of $U 3$, and no necrosis was observed in most plants up to 14 DPI. Common bermudagrass (C. dactylon) was not included in the studies conducted by Caasi et al. (3) as these cultivars are often utilized in situations where lesser management inputs do not encourage SDS.

As Caasi et al. (3) reported for $O$. herpotricha, in this study stolons were colonized by $O$. korrae only superficially, unless a wound was present. Pseudothecia of $O$. korrae and $O$. narmari are commonly observed on infected stolons in Australia but appear to be produced rarely under field conditions in the United States 
$(12,26)$. Crahay (4) produced fruiting bodies in vitro using nonsterile plant material. In this study, $O$. korrae was recovered from dead stolon tissues nine months after infection (data not shown): however, pseudothecia production by either wild-type or transformed isolates in sterile bermudagrass plants did not occur. The scarceness of fruiting bodies and absence of sclerotia suggests that dispersal likely occurs mainly through the movement of infested plant material (14). In addition, stolons could be both a source of inoculum and an over-summering site for the fungus when bermudagrass growth is favored.

While $O$. korrae readily colonized the roots of all cultivars tested, widespread necrosis was associated only with cultivars that prevented vascular colonization. The mechanisms used to impede or permit colonization of the stele is unknown, but represents a promising target for future research. The effects of Ophiosphaerella spp. colonization of the stele on bermudagrass growth and survival have not been studied. Fungal growth inside the vascular tissue may have a negative effect on the movement of water and nutrients through the root system. Nevertheless, a study by Flores et al. (9) examined the production of reactive oxygen species (ROS) by bermudagrass roots in response to Ophiosphaerella spp. colonization and indicated that plant generated ROS increased when the fungus colonized the stele and this may suggest an endophytic association. Overall, infection and colonization of bermudagrass by $O$. korrae resembles that of $O$. herpotricha for those cultivars examined. Therefore, similar management strategies, such as breeding for cultivars with better field resistance, may be applicable to both species. These breeding efforts may be enhanced through evaluation of the in vitro responses of prospective bermudagrass cultivars to infection and colonization by O. korrae or O. herpotricha.

\section{ACKNOWLEDGMENTS}

Published with the approval of the Director, Oklahoma Agricultural Experiment Station, Stillwater, OK. This project was supported in part by the United States Golf Association and Oklahoma Agricultural Experiment Station project 2833 . We thank D. Perry and M. Tomaso Peterson who collected the $O$. korrae isolate used in the study.

\section{LITERATURE CITED}

1. Anderson, J. A., Taliaferro, C. M., and Martin, D. L. 1993. Evaluating freeze tolerance of bermudagrass in a controlled environment. HortScience 28:955.

2. Baird, J. H., Martin, D. L., Taliaferro, C. M., Payton, M. E., and Tisserat, N. A. 1998. Bermudagrass resistance to spring dead spot caused by Ophiosphaerella herpotricha. Plant Dis. 82:771-774.

3. Caasi, O. C., Walker, N. R., Marek, S. M., Enis, J. N., and Mitchell, T. K. 2010. Infection and colonization of turf-type bermudagrass by Ophiosphaerella herpotricha expressing green or red fluorescent proteins. Phytopathology 100:415-423.

4. Crahay, J. N. 1988. Growth and pathogenicity of Leptosphaeria korrae in bermudagrass. Plant Dis. 72:945-949.

5. Dale, J. L., and Diaz, C. 1963. A new disease of bermudagrass turf. Ark. Farm Res. 12:6.

6. Dernoeden, P. H., Zhang, M., and Wetzel, H. C. 1995. First report of necrotic ring spot (Leptosphaeria korrae) in creeping red fescue in Maryland. Plant Dis. 79:966.
7. Dunn, J. H., Nelson, C. J., and Sebaugh, J. L. 1980. Characterization of thatch, rhizomes, carbohydrates, and spring deadspot in twenty cultivars of bermudagrass. J. Am. Soc. Hortic. Sci. 105:653-660.

8. Endo, R. M., Ohr, H. D., and Krausman, E. M. 1985. Leptosphaeria korrae, a cause of the spring dead spot disease of bermudagrass in California. Plant Dis. 69:235-237.

9. Flores, F., Marek, S., Anderson, J., Mitchell, T., and Walker, N. Reactive oxygen species production in response to Ophiosphaerella spp. colonization of bermudagrass roots. Acta Hortic. (In press.)

10. Green, D. E. 1993. Pathogenicity of Rhizoctonia solani AG-2-2 and Ophiosphaerella herpotricha on zoysiagrass. Plant Dis. 77:1040-1044.

11. Iriarte, F. B., Fry, J. D., Martin, D. L., Todd, T. C., and Tisserat, N. A. 2005. Effect of cold acclimation and freezing on spring dead spot severity in bermudagrass. Hortic. Sci. 40:421-423.

12. Jackson, N. 1993. Geographic distribution, host range, and symptomatology of patch diseases caused by ectotrophic fungi. Page 161 in: Turfgrass patch diseases caused by ectotrophic root-infecting fungi. B. Clarke and A. B. Gould, eds. American Phytopathological Society, St. Paul, MN.

13. Lagopodi, A. L., Ram, A. F. J., Lamers, G. E. M., Punt, P. J., Van den Hondel, C. A. M. J. J., Lugtenberg, B. J. J., and Bloemberg, G. V. 2002. Novel aspects of tomato root colonization and infection by Fusarium oxysporum f. $\mathrm{sp}$. radicis-lycopersici revealed by confocal laser scanning microscopic analysis using the green fluorescent protein as a marker. Mol. Plant-Microbe Interact. 15:172-179.

14. Landschoot, P. J. 1993. Ecology and epidemiology of ectotrophic rootinfecting fungi associated with patch diseases of turfgrasses. Page 161 in: Turfgrass Patch Diseases Caused by Ectotrophic Root-Infecting Fungi. B. B. Clarke and A. B. Gould, eds. American Phytopathological Society, St. Paul, MN.

15. Lucas, L. T. 1980. Spring deadspot of bermudagrass. Pages 183-187 in: Advances in Turfgrass Pathology. B. G. Joyner and P. O. Larsen, eds. Harcourt \& Brace Jovanovich, Inc., Duluth, MN

16. Martin, D. L., Bell, G. E., Taliaferro, C. M., Tisserat, N. A., Baird, J. H., Dobson, D. D., Kuzmic, R. M., and Anderson, J. A. 2001. Spring dead spot resistance of inter-specific hybrid bermudagrasses. Int. Turf Soc. Res. J. 9:685-688.

17. Olivain, C., and Alabouvette, C. 1999. Process of tomato root colonization by a pathogenic strain of Fusarium oxysporum f. sp. lycopersici in comparison with a non-pathogenic strain. New Phytol. 141:497-510.

18. Raffle, V. L., and Hsiang, T. 1998. Low level of DNA polymorphisms in isolates of Leptosphaeria korrae pathogenic on Poa pratensis. Can. J. Plant Pathol. 20:48-54.

19. Smiley, R. W., Dernoeden, P. H., and Clarke, B. B. 2005. Compendium of Turfgrass Diseases, 3rd Ed. The American Phytopatological Society, St. Paul, MN.

20. Smith, A. M. 1965. Ophiobolus herpotrichus a cause of spring dead spot in couch turf. Agric. Gaz. New South Wales 76:753-758.

21. Tisserat, N., Wetzel, H., Fry, J., and Martin, D. L. 1999. Spring dead spot of buffalograss caused by Ophiosphaerella herpotricha in Kansas and Oklahoma. Plant Dis. 83:199.

22. Tisserat, N. A., Pair, J. C., and Nus, A. 1989. Ophiosphaerella herpotricha, a cause of spring dead spot of bermudagrass in Kansas. Plant Dis. 73:933-937.

23. Tredway, L. P., and Butler, E. L. 2007. First report of spring dead spot of zoysiagrass caused by Ophiosphaerella korrae in the United States. Plant Dis. 91:1684.

24. Tredway, L. P., Tomaso-Peterson, M., Perry, H., and Walker, N. R. 2009. Spring dead spot of bermudagrass: A challenge for researchers and turfgrass managers. Plant Health Progress. doi:10.1094/PHP-2009-0710-01-RV.

25. Wadsworth, D. F., and Young, H. C. 1960. Spring dead spot of bermudagrass. Plant Dis. Rep. 44:516-518.

26. Walker, J., and Smith, A. M. 1972. Leptosphaeria narmari and L. korrae spp. nov., two long-spored pathogens of grasses in Australia. Trans. Br. Mycol. Soc. 58:459-466.

27. Wetzel, H. C., Skinner, D. Z., and Tisserat, N. A. 1999. Geographic distribution and genetic diversity of three Ophiosphaerella species that cause spring dead spot of bermudagrass. Plant Dis. 83:1160-1166. 